\title{
ANPUH: contribuições e limites nas definições sobre o ensino de História
}

Margarida Maria Dias de Oliveira ${ }^{1}$

\section{RESUMO}

0 texto analisa a participação da Associação Nacional de História - ANPUH, no Diagnóstico e Avaliação dos Cursos de História no Brasil (1981-1986) e as contribuições para a discussão sobre o profissional de História que se deseja formar como também indica algumas questões sobre as quais seria desejável o aprofundamento do debate.

Palavras-chave: ANPUH, avaliação, profissional da história

Consideramos infundada a assertiva sobre o diminuto espaço concedido às questões do ensino na internalidade da ANPUH. Contudo, faz-se necessário observar e discutir o fato de essa entidade, que já acumulou um razoável debate sobre o ensino, não ter conseguido colocar em pauta a questão fulcral: parâmetros para o ensino de História.

Uma das ocasiões que a ANPUH teve oportunidade de discutir estes parâmetros foi o Diagnóstico e Avaliação dos Cursos de História no Brasil (19811986). Em 1981, a proposta do MEC era elaborar um novo currículo mínimo para os Cursos de Graduação em História. Contudo, os consultores convidados ${ }^{2}$ argumentaram que não cabia a eles proporem uma mudança de tal envergadura, e que consideravam importante, para se chegar a qualquer modificação, antes

1 Professora do UNIPÊ/João Pessoa/PB.

2 "O Grupo de Consultores (GC) foi constituído, inicialmente, pelos professores Francisco José Calazans Falcon/UFF (relator), Déa Ribeiro Fenelon/UNICAMP (Coordenadora), Adalgisa Maria Vieira do Rosário/ UnB (Secretária), Alicer Piffer Canabrava/Presidente da ANPLH, João Batista Pinheiro Cabral/UnB, Joana Neves/UFPB, Maria José Féres Ribeiro/UFJF e Antônio José Barbosa/SESu-MEC. Posteriormente, a partir da segunda reunião do Grupo de Consultores, foi sugerida a inclusão das professoras Ruth Morais/UFPA e Sandra atahy Pesavento/UFRGS, e a professora Alice Canabrava foi substituída pelo professor José Ribeiro Júnior, novo presidente da ANPUH." (relatório, p 6). 
proceder a um mapeamento das condições dos Cursos e, aproveitando o trabalho, colocar a discussão em pauta para a comunidade acadêmica.

Definindo-se desde sua reunião de instalação como instância mediadora de uma discussão mais ampla, cujo verdadeiro núcleo deveriam ser os diversos Departamentos de História (professores e alunos), o Grupo de Consultores procurou assumir sempre esta postura, reconhecendo que nenhuma de suas atividades deveria ter caráter normativo ou decisório. ${ }^{3}$

0 Grupo de Consultores, que se constituiu por representantes das regiões brasileiras, era presidido pelo Presidente da Associação Nacional de História. Portanto, o trabalho foi feito com financiamento (pagamento de passagens e hospedagens para reuniões em Brasília) e tinha caráter oficial do Ministério da Educação, mas dirigido pela ANPUH.

0 "Projeto Diagnóstico e Avaliação dos Cursos de História no Brasil" foi um trabalho desenvolvido a partir de 1981, com o apoio da Secretaria de Educação Superior - SESu/MEC, com o objetivo de "diagnosticar e avaliar os Cursos de História existentes no país, visando levantar questões fundamentais e definir com clareza as linhas básicas da licenciatura e do bacharelado, principalmente em termos de objetivos a alcançar." ${ }^{\prime \prime}$

0 documento final foi publicado em maio de 1986 e condensou um relatório das atividades desenvolvidas pelo Grupo de Consultores, o qual produziu um primeiro documento, explicando os objetivos do trabalho, que foi encaminhado aos diversos Cursos de História, sendo adotado, como estratégia para alcançar um grupo sempre mais representativo desses Cursos, a utilização de todas as atividades desenvolvidas pela ANPUH.

Assim, por exemplo, no XI Simpósio Nacional da ANPUH, ocorrido em João Pessoa/PB, em 1981, foi realizada uma mesa-redonda sobre esse trabalho e, segundo o relatório, "com expressiva participação de professores de vários Departamentos de História e um grande número de alunos que, na ocasião, reivindicaram sua participação no trabalho do GC, ficando esclarecido que

3 MEC/SESu. Diagnóstico e avaliação dos Cursos de História no Brasil. Documento Final. Brasilia, 1986. p. 6. 4 MEC/SESu. Diagnóstico e avaliação dos Cursos de História no Brasil. Documento Final. Brasília, 1986. p. 6 
esta participação, sempre incentivada e desejada pelo GC, dar-se-ia através das discussões nos Departamentos."

Respondidos os questionários por vários Departamentos de História e devolvidos à SESu/MEC, o Grupo de Consultores sistematizou um novo documento com as questões trabalhadas e o reencaminhou às instituições de ensino para uma nova discussão, solicitando o retorno, em forma de documento, do desdobramento do debate. 0 Relatório ressalta que essa segunda demanda do Grupo de Consultores não foi atendida pela maioria dos Cursos.

0 Relatório inclui, ainda, a condensação dos dados dos questionários em dez pontos, a saber:

1) Dados gerais sobre o corpo docente;

2) Período de funcionamento do curso de graduação em História;

3) Informações sobre o alunado;

4) Estrutura do Departamento de História;

5) Ciclo básico;

6) Introdução aos Estudos Históricos;

7) Bacharelado e Licenciatura;

8) Articulação com o ensino de $1^{\circ}$ e $2^{\circ}$ graus; [obs.: nomenclatura da época, Lei 5692]

9) Pesquisa;

10) Interação entre as disciplinas.

Ao segundo documento enviado pelo grupo de consultores, apenas 12 instituições de ensino responderam, a partir do que foi condensado um novo documento que dividiu as questões em três grupos. No Grupo A, os pontos foram: Currículo Mínimo, Licenciatura e Bacharelado, Ensino e Pesquisa, Ciclo Básico e Disciplinas Teóricas; no Grupo B, foram sistematizados dois temas: Relação com o ensino de $1^{\circ}$ e $2^{\circ}$ graus e a Legislação do ensino e a questão dos Estudos Sociais; e, no Grupo C, Trabalho docente, Relações entre graduação e pós-graduação, Relações com as áreas afins, Estrutura da universidade, Carreira docente e Recursos materiais.

5 MEC/SESu. Op. Cit. p. 7. 
Foi produzido um texto pelo Grupo de Consultores sobre A questão de Estudos Sociais ${ }^{6}$, assim intitulado, além de um documento conclusivo. Ao final da publicação, há a propositura de um Programa de Melhoria do Ensino de Graduação em História - PMEG/História e vários quadros estatísticos dos Cursos.

Apesar de ter sido feita a partir de profissionais de História e, da amplitude, longevidade, representatividade do trabalho, e de analisar questões essenciais (algumas conjunturais, outras estruturais), a discussão sobre a definiç̧ão do conhecimento histórico, esperado e devido ao cidadão brasileiro, não surgiu.

Embora o Diagnóstico seja rico em reflexões e tenha sistematizado informações sobre 131 (cento e trinta e um) cursos de graduação em História no Brasil, alcançando, desta forma, um quadro da diversidade nacional e encaminhando, para dentro da categoria, o debate sobre os Cursos de Graduação, não conseguiu redimensionar a discussão no sentido da comunidade acadêmica ver uma necessidade do debate mais fundo, além das alterações do currículo mínimo ou de reorganização das disciplinas.

Ou, de posse do importante mapeamento, nem o Ministério da Educação nem a ANPUH encaminharam a discussão de quais seriam os passos adiante. Como as questões salariais, de condições de trabalho e de pesquisa eram visivelmente mais precárias nas instituições particulares, confirmou-se uma outra dicotomia (instituições públicas x privadas), e a discussão sobre a formação do profissional de História ficou confinada, mais uma vez, à particularidade de cada instituição. Os profissionais de História, novamente, protelaram a definição sobre o direito ao passado.

0 debate mais próximo a essa questão se restringiu, sempre, à defesa de reformas que deveriam ser efetivadas no Currículo Mínimo:

Salvo um único caso de defesa do atual currículo, inclusive contra sua redução, e dois casos de sugestões visando reformas parciais, as demais propostas configuram

\footnotetext{
${ }^{6}$ A, assim chamada, questão de Estudos Sociais dizia respeito à transformação das disciplinas História, Geografia, Sociologia e Filosofia em "áreas de ensino", além de acrescentar o ensino da EMC e OSPB e da criação das Licenciaturas que deveriam formar o profissional para esse ensino. Como já assinalado no Capítulo 1, essa foi uma da lutas que mais mobilizou a ANPUH e, nesta ocasião, o Grupo de Consultores aproveitou para, mais uma vez, demonstrar, por meio dos dados, a ineficácia da suposta formação.
} 
o que se poderia chamar de reforma radical. Variam, aí, entretanto, as concepções concretas a respeito de como deveria ser o novo currículo. Parece, todavia, que se pode perceber uma primeira dicotomia: os que crêem na eficácia do currículo e julgam que o importante é elaborar um que seja o melhor possível; e aqueles que descrêem quase totalmente dessa eficácia, considerando-0 apenas um efeito secundário de opções mais importantes. Estes últimos valorizam, por exemplo, a necessidade de um "eixo básico de desenvolvimento do curso", a possibilidade de novas experiências e, sobretudo, uma "concepção global" e uma clara "opção metodológica". Indo mais além, colocam como ponto de partida o questionamento das concepções vigentes sobre a História, enquanto ciência e enquanto disciplina. $[\ldots]$

Em síntese, pareceu ao GC que a questão do currículo revela-se como das mais importantes, ou a mais importante, embora, no atual estágio de sua discussão, seja impossível estabelecer um consenso sobre o que deve ser mudado, se bem que haja consenso quanto à necessidade de mudar?

Vale salientar que toda essa discussão dizia respeito ao currículo mínimo, o que é muito imporiante observar, pois o consenso da mudança não se acompanhava de uma clareza do que mudar, embora alguns princípios fossem apontados, como:

[...] a licenciatura não pode ser pensada como problema específico dos pedagogos e sim, basicamente, como Curso de História, única maneira de fazer frente ao grave problema que é a profunda diferença entre a concepção de História dos respectivos profissionais e a visão que têm da História os pedagogos.

$[\ldots]$

Pontos comuns observados:

$1^{\circ}$ Contra a definição das disciplinas pedagógicas sem articulação prévia com os Departamentos diretamente interessados;

$2^{\circ}$ Contra a valorização dos instrumentos ou técnicas didáticas em detrimento dos conteúdos;

\footnotetext{
${ }^{7}$ MEC/SESu. Diagnóstico e avaliação dos Cursos de História no Brasil. Documento Final. Brasília, 1986. p. 13.
} 
$3^{\circ}$ Contra qualquer dicotomia do tipo "conteúdo x profissionalização";

$4^{0}$ Não é suficiente que a "prática de ensino" seja lecionada por professores com licenciatura em História; é preciso uma presença real e permanente do Departamento nessa matéria.

Em síntese, parece ao GC que existe uma tendência a rejeitar a dicotomia licenciatura x bacharelado, especialmente porque, entre outras, ela tende a reforçar sérios desvios e deformações no âmbito da licenciatura em detrimento da boa formação do professor de História. Há necessidade de maior entrosamento entre os Departamentos de História os Departamentos ou Faculdades de Educação (debates, encontros, seminários, presença recíproca de docentes nos Departamentos), pois há um longo caminho a percorrer ainda em função do conflito entre as concepções de História vigentes entre os historiadores e os pedagogos. ${ }^{8}$

A contundência da dicotomia disciplinas de conteúdo e disciplinas pedagógicas é traduzida, assim, na oposição de concepções históricas entre historiadores e pedagogos. Subliminarmente, transparecem críticas a esses profissionais pela sua desconexão com os cursos de História.

É relativamente fácil compreendermos esse posicionamento de ataque dos historiadores aos pedagogos se pensarmos na preponderância que foi concedida ao pedagogismo na formação dos profissionais das licenciaturas após a lei 5692/71. Contudo, podemos aferir, também, que esse espaço foi ocupado com maior rigor pela incapacidade - assumida nas citações acima dos historiadores afirmarem quais suas demandas e como se daria essa integração, para além das atividades aventadas, na formação do profissional de História.

Faz-se necessário esclarecer o que estamos considerando aqui pedagogismo, pois, se a exacerbação dessas idéias se deram na vigência da lei 5697/71, ou seja, durante a ditadura militar, elas não deixaram de se renovar e continuamos convivendo com elas.

0 que estamos chamando pedagogismo, não desmerece os pedagogos, tampouco seus cursos. Diz respeito, sim, a um conjunto de idéias que defenderam a predominância dos recursos técnicos sobre o conteúdo a ser ensinando,

8 MEC/SESu. Diagnóstico e avaliação dos Cursos de História no Brasil. Documento Final. Brasília, 1986. p. 14 e 15 . 
criando uma falsa expectativa de que, sabendo-se usar determinados recursos, ensinar-se-ia qualquer conteúdo.

É sobre a introdução massificada dessas idéias no ensino e da sua suposta desvinculação política, a que se referia o Professor Helius Skiner, em seu depoimento transcrito no Capítulo 1, como também, é sobre essa deturpação a substituição da reflexão do que e como ensinar pelas receitas de aulas - que reclamam, por exemplo, os formandos que vivenciam determinadas experiências nos cursos de formação de professores:

Na HEM [Habilitação Específica de $2^{\circ}$ grau para o Magistério], a maioria das alunas trabalha em pré-escolas de rede particular, e os Planos de Ensino de Didática têm atendido às solicitações feitas de "ensino de modelitos" prontos para as festas escolares, tais como os de caras de coelhos e ovos decorados com lantejoulas, para a comemoração da Páscoa; flores de papel crepom e bandeirolas para as festas juninas; a espada de D. Pedro para a comemoração da Semana da Pátria; um saci engraçadinho para comemorar o folclore, além da "pasta de mil e uma utilidade", com modelos para serem reproduzidos no mimeógrafo a álcool e utilizado nas atividades diárias da escola.

Pouco espaço existe para discussão e análise dos problemas levantados da prática das escolas de pré a $4^{\mathrm{a}}$ série do $1^{\circ}$ grau. Nos planos de ensino da HEM, não se tem observado a presença de diferentes disciplinas fornecendo subsídios para a compreensão dos determinantes dessa prática. ${ }^{9}$

Além disso, a idéia, na sua essência correta, da formação de um profissional de História (nem só professor, nem só pesquisador), na realidade vivida em nosso país, favoreceu colocar em segundo plano a discussão relativa à formação do professor. A concretude de desvalorização desse profissional, inclusive social, aliada às muitas hierarquias construídas pela academia, ajudou a encobrir, em um manto de vergonha, as sempre necessárias e urgentes questões da formação do professor, embora fosse e continue sendo a sala de aula o maior mercado de trabalho para os profissionais de História.

\footnotetext{
9 PICONEZ, Stela C. Bertholo. A Prática de Ensino e o Estágio Supervisionado: a aproximação da realidade escolar e a prática da reflexão. In: PICONEZ, Stela C. Bertholo (coord.) et al. APrática de Ensino e o estágio supervisionado. Campinas/SP: Papirus, 1991. (Coleção Magistério: formação e trabalho pedagógico).
} 
0 outro lado dessa moeda, a relação com 0 ensino de $1^{\circ}$ e $2^{\circ}$ graus (assim chamado na época), não melhora em nada essa concepção:

Basicamente houve o reconhecimento geral de que tal articulação simplesmente não existe. 0 maior problema parece ser exatamente "achar a fórmula" que permita estabelecer essa articulação e romper assim com os diversos tipos de isolamento que caracterizam, hoje, a atividade departamental. Em alguns casos há fortes indicações de que existe a consciência bem nítida do problema e mesmo alguns esforços mais sérios vêm sendo realizados em algumas universidades no sentido de mudar a situação. Uma das sugestões recebidas foi exatamente a de criar em cada Departamento uma equipe ou grupo de trabalho voltado para o equacionamento de tais problemas, com o objetivo, inclusive, de organizar ciclos de estudos, debates, conferências, seminários, para fazer uma constante avaliação dos livros didáticos, oferecer assessoramento aos estabelecimentos de ensino de $1^{\circ}$ e $2^{\circ}$ graus, estabelecer contactos freqüentes com as secretarias de educação estaduais e municipais, etc. As atividades de extensão vêm sendo, em alguns casos, desenvolvidas justamente nessa direção. Um outro argumento, algo freqüente, foi o da necessidade de repensar os cursos e a atividade departamental cada vez mais em função das perspectivas regionais, pois, acredita-se, este seria um meio de obter maior entrosamento entre a universidade e os outros níveis educacionais. ${ }^{10}$

Ou seja, o pedagogismo é o resultado de uma mistura muito perniciosa, composta por: prevalência da técnica como solução para os problemas da educação - o que se expressa agora na questão da utilização de todos os recursos eletro-eletrônicos (tv/vídeo, parabólicas, computador, Internet, tudo apontado para a diminuição não só da importância como da presença dos professores) e 0 alheamento dos profissionais das áreas específicas dos cursos superiores, no que nos interessa, de História, resultando na falta de diálogo entre as duas áreas que deveriam formar o profissional: a específica e a pedagógica.

Contudo, a prevalência da técnica sobre o conteúdo também respondeu a um apelo da sociedade que, cada vez mais, tem demandado da escola a

\footnotetext{
${ }^{10}$ MEC/SESu. Diagnóstico e avaliação dos Cursos de História no Brasil. Documento Final. Brasília, 1986. p. 16 e 17 .
} 
utilização de todo aparato eletro-eletrônico que caracteriza o modelo de vida, sobretudo, da classe média. Isto, porém, não pode ser encarado apenas como se fosse a escola andar pari passu com a sociedade. Significa a utilização de novas linguagens, proporciona novas relações e novos serviços que ainda não foram suficientemente avaliados. Fazendo alguns caricaturarem assim:

Os jovens são tratados nas escolas como consumidores que não podem ser entediados. Construiu-se uma parafernália de discursos especializados para tentar eliminar o conflito, as dores da aprendizagem. Os professores já não podem - as vezes não querem - exigir trabalho duro dos seus alunos, busca-se mecanismo para tornar as aulas mais interessantes - jogos, vídeos, etc

Eu pergunto: Desde quando aprender foi fácil? Como épossível que os jovens aprendam o funcionamento, as regras do mundo adulto, de responsabilidades, se eles são tratados como adultos que possuem todos os direitos mas nenhuma obrigação? E o que acontece quando não cumprem com o mínimo - ah! É um problema de aprendizagem: chamem o psicólogo, o pedagogo, o orientador, o diretor, o advogado, os pais, o delegado de ensino, o governador. E o professor, como é que fica?

Problemas existem, mas a terapeutização do cotidiano retirou a autoridade - não 0 autoritarismo - do professor - que é quem efetivamente vivencia o processo. ${ }^{11}$

É claro que as observações feitas nas citações acima retratam situaçõeslimite das dificuldades que a formação e a atuação de professores têm enfrentado. De qualquer forma, consideramos que representam os sintomas de que a instituição de ensino superior, de forma geral, não tem proporcionado uma formação ao profissional de modo que este se sinta seguro para exercer sua profissão. As relações universidade/escola ainda se caracterizam pela dicotomia teoria/prática.

Assim, mesmo no Diagnóstico feito pela ANPUH/MEC, ou justamente por isso, a idéia de entrosamento universidade/escola é vista, exclusivamente, como possibilidade de a universidade fornecer pessoal especializado para assessorias, a sempre citada reciclagem de professores e, até, de avaliação de livros didáticos. Numa espécie de tutoria, a universidade não alarga sua visão

${ }^{11}$ ARRUDA, Gilmar. 0 professor de História e a contemporaneidade. Texto não publicado, 1995. 
ultrapassando a idéia de ensinar a escola, embora não tenha definido, para além da listagem de conteúdos, o que exigir do estudante, como conhecimento, competências e habilidades - para usar as nomenclaturas tão caras aos PCN - na sua formação inicial de futuro profissional, entendendo-se por isso, a apropriação de um conhecimento específico para o qual será necessária, dentre outras coisas, a formação geral que deve ter sido garantida até o ensino médio. A não concretização disso tem provocado o fenômeno conhecido como secundarização ${ }^{12}$ da graduação, significando no caso dos Cursos de História, a necessidade de apreensão de informações e hábitos de leitura e habilidades de interpretação e análises, por exemplo, que comprometem o funcionamento da graduação como real iniciação à pesquisa, embora não seja 0 único fator.

0 debate sobre 0 direito ao passado, a ser feito pelos historiadores, tornase, assim, mais importante porque ele definirá não só sua formação, mas o que, do ponto de vista do conhecimento histórico, em cada etapa, é essencial que 0 aluno-cidadão aprenda. Essa definição não tem nada de uma tutoria dos historiadores em relação aos cidadãos, mas a clareza da necessidade dessa definição por quem constrói e sabe (ou deve saber) como se constrói esse conhecimento e, portanto, a reflexão da possibilidade de aprendizado a partir das fases de crescimento do ser humano, definidos pela psicologia cognitiva. ${ }^{13}$ Esse seria um saber profissional que responderia às demandas da sociedade. Contudo, nem foram fomentadas, nem apontadas pelo Diagnóstico.

As conclusões do Diagnóstico sistematizam questões importantíssimas, todas relacionadas, como bem reconhece o próprio documento, com 0 "problema que perpassa todos os debates: trata-se da definição do 'profissional de História' que se quer formar". ${ }^{14}$ Estão divididas em três pontos, sendo o primeiro sobre o profissional de História e o mercado de trabalho. Faz-se importante observar os dois trechos abaixo:

\footnotetext{
${ }^{12}$ Secundarização da graduação tem sido denominado, comumente, o fenômeno que tem gerado a necessidade de, na graduação, serem supridas deficiências provenientes do ensino médio (antigo curso secundário e de $2^{\circ}$ grau, daí o nome). Foi esta constatação que gerou propostas com cursos de "nivelamento", ou seja, cursos na Universidade, no $1^{\circ}$ período, para "nivelar", suprir deficiências.

${ }^{13}$ Este é um outro debate que, como a relação sociedade/escola, também se encontra muito avançado. Se Piaget é o marco inicial dessas reflexões, ou seja, o que se aprende e como se aprende, contribuições como as de Vigotski e Perrenoud são referências fundamentais.

${ }^{14}$ MEC/SESu. Diagnóstico e avaliação dos Cursos de História no Brasil. Documento Final. Brasília, 1986. p. 27.
} 
Como observação inicial podemos constatar que, na direção em que vem caminhando a maioria dos Cursos de História, no Brasil, não existe uma preocupação dominante com a formação completa do profissional de História. Isto significa dizer que, a rigor, o atual ensino de História, nas diversas escolas, faculdades isoladas e universidades, têm suas preocupações e definições voltadas acentuadamente para a preparação de profissionais do ensino, cuja habilitação é realizada nas Faculdades de Educação, quase sempre em completa desarticulação com os Departamentos de História, o que resulta, muitas vezes, em uma formação bastante deficiente. ${ }^{15}$

Ou seja, temos aqui dois problemas: da predominância da formação do professor e dessa formação se dar, no mais das vezes, com preponderância dos Departamentos ou Faculdades de Educação, sem a devida articulação com a formação específica:

Outra observação que desejamos salientar é a de que a maioria desses cursos de História é bastante livresca, no sentido de que ainda se pensa a História a ser transmitida como calcada apenas na informação que está nos manuais, nas grandes obras, etc., consagrando-se muitas vezes não apenas o mito da palavra escrita mas, principalmente, a confusão entre a historiografia e o processo histórico acontecido. Isto porque os cursos, que quase nunca recorrem à prática da pesquisa, sobretudo no espaço da graduação onde a importância desta atividade para a formação é mais sentida, assimilaram a idéia de que a atividade de pesquisa não é necessária ao ensino. ${ }^{16}$

E aqui a assunção de que os cursos de História também não preparam bem seus profissionais, que, restringindo-se ao livresco, não compreendem como se dá a construção do conhecimento histórico.

Sintomaticamente, o segundo ponto que condensa as conclusões do Grupo de Consultores, intitulado Articulação da Universidade com o Ensino de $1^{\circ}$ e $2^{\circ}$ Graus, além de reconhecer o caráter de julgamento que os cursos

\footnotetext{
${ }^{15}$ MEC/SESu. Op. Cit. p. 27.

${ }^{16}$ MEC/SESu. Op. Cit. p. 27.
} 
adotam em relação à escola dessas etapas da Educação Básica, chamam a atenção para a inadequação dos cursos superiores à realidade escolar, observando que a defasagem se dá em "quatro pontos fundamentais para o ensino de História": conteúdo, teoria e metodologia, relação ensino-pesquisa e técnicas didático-pedagógicas. E conclui:

Da colocação destes pontos, a conclusão a que se chega é a de que toda e qualquer proposta de reestruturação dos cursos de história, bem como qualquer revisão do currículo, mínimo ou pleno, exige que se analise a relação entre eles e o ensino de $1^{\circ} \mathrm{e} 2^{\circ}$ graus, no sentido de estabelecer a necessária articulação. ${ }^{17}$

\section{E sugere:}

Em primeiro lugar, seria necessário, por exemplo, que $01^{\circ}$ e $2^{\circ}$ graus fossem objeto de estudo, de análise e de reflexão nos cursos de graduação. E o importante é que esse estudo fosse realmente feito ao longo de todo o curso e não se limite apenas a estágios finais, quando todas as disciplinas do curso já foram desenvolvidas. De forma específica, esta poderia ser, por exemplo, a primeira preocupação da disciplina "Estrutura e Funcionamento do Ensino de $1^{\circ}$ e $2^{\circ}$ graus" que, atualmente, se volta quase que exclusivamente para estudos da legislação vigente. E seria absolutamente imprescindível que, nessas análises, se colocassem os problemas específicos da História.

Uma segunda indicação diz respeito à posição específica que se quer atribuir ao ensino universitário na articulação com os demais. Será somente na universidade que os profissionais deverão ser treinados para a reflexão sobre todo o processo de produção do conhecimento histórico? Seria possível falar-se em etapas ou fases a serem cumpridas em cada nível de ensino de acordo com 0 grau de maturidade dos estudantes? Haveria que se discutir um pouco mais sobre o significado do ensino de História, entendido sempre como produção do conhecimento, para que se pudesse também refletir sobre o que queremos dizer quando falamos de instrumentação do profissional. ${ }^{18}$

\footnotetext{
${ }^{17}$ MEC/SESu. Diagnóstico e avaliação dos Cursos de História no Brasil. Documento Final. Brasilia, 1986., p. 30. ${ }^{18}$ MEC/SESu. Op. Cit. p. 30.
} 
o Grupo de Consultores deixou passar uma ótima oportunidade de transformar esses questionamentos em princípios e, a partir destes, sugerir parâmetros que norteassem o ensino de História. Talvez por propostas de modelos nacionais ainda parecerem como impositivos ditatoriais, apesar de se estar vivendo, naquele momento, os primeiros ventos redemocratizantes da sociedade brasileira. Talvez por respeito à diversidade ou mesmo pelo Grupo de Consultores não ter definido isso como objetivo final. Qualquer que seja a explicação, a ANPUH e o MEC, dessa vez, unidos, não chegaram ao ponto crucial da questão.

Inexplicavelmente, o Diagnóstico não foi utilizado nem pelo Ministério da Educação nem pela ANPUH. Documento importante para conhecimento da realidade dos Cursos de Graduação em História no país, naquele momento, restringiu-se a uma publicação de pequena tiragem e à divulgação apenas entre alguns interessados.

A categoria de professores de História, algumas vezes, manteve conflitos com as determinações governamentais que ora restringem, ora tentam moldar a sua forma de atuação. Em outros momentos, a ANPUH legitimou comissões, indicando nomes ou participando como entidade, como foi o caso do Diagnóstico. Porém, se a ANPUH fosse hoje chamada para implementar o que quer do ensino de História, não teria como agir, seja por se contrapor às tentativas de uniformização, seja por entendimento insuficiente da questão ou por haver até agora pouco esforço para a construção do consenso necessário ${ }^{19}$.

Mais uma vez, perdeu-se uma ótima oportunidade de discutir quais os referenciais históricos que seriam direito e dever do cidadão apreender para que pudesse ler o seu mundo e nele atuar, ou seja, o seu direito ao passado

\footnotetext{
${ }^{19}$ Vale salientar que a construção do consenso, no nosso entender, seria para fixação de parâmetros gerais que norteassem o ensino de História, mas não impedisse, em hipótese nenhuma, a expressão, nos vários locais, da diversidade nacional.
} 


\section{Bibliografia}

ABUD, K. M. Professor, professores: um perfil dos professores de História da rede estadual paulista. Comunicação apresentada ao IX ENDIPE, Águas de Lyndóia, 1998 (texto digitado).

APPLE, M. W. Trabalho docente e textos: economia política das relações de classe e gênero em educação. Porto Alegre: Artes Médicas, 1995.

BARCA, I. A educação histórica na sociedade de informação. O Ensino de História. Publicação Quadrimensal. Boletim da APH, n. 19/20, p. 35-42, fev. jun. 2001.

BASSO, I. S. As concepções de História como mediadoras da prática pedagógica do professor de História. Didática. São Paulo, n. 25, p. 1-10, 1989. Veja-se também versão revista do mesmo artigo In: DAVIES, N. (org). Para além dos conteúdos do ensino de História. Niterói: EdUFF, 2000, p. 45-60.

BOURDIEU, P. O poder simbólico. $4^{\mathrm{a}}$ ed. Rio de Janeiro: Bertrand Brasil, 2001.

CAMARGO, D.M.P, ZAMBONI, E. e GALZERANI, M. C. B. Sabor e dissabores do Ensino de História. Revista Brasileira de História. São Paulo: v. 9, nº 19, pp. 181-195, set. 89/fev. 90.

CAUTERMAN, M.M. et allii. La formation continue des enseignants est-elle utile? Paris: Presse Universitaire de France, 1999.

IMBERNÓN, F. La formación y el desarrollo profesional del profesorado: hacia una nueva cultura profesional $5^{\mathrm{a}}$ ed. Barcelona: Graó, 2002. (Biblioteca de Aula, 119)

LEE, Peter. Walking backward into tomorrow. Historical conscieousness understanding history. History in education. Unit School of Arts and Humanities. University of London Institute of Education. Paper given at Annual Meeting of American Research Association, New Orleans. 2002.

LORENZI, M. G. R., CEZNE, A. N., MONTAGNER, R.; CUNHA, J. L. Concepções do ensino de História no processo de formação. In: SCHMIDT, M.A. e CAINELLI, M. III Encontro Perspectivas do Ensino de História. Curitiba: Aos quatro ventos, 1999, p. 67-75.

POPKEWITZ, Gubernamentalidad y formación docente. In: BIRGIN, A. et alli. La formación docente: cultura, escuela y política. Debates y experiencias. Buenos Aires (Arg.): Troquel Educación, 1998, p. 67-72 (Serie FLACSO Acción), p. 55-66.

SCHIMIDT, M. A. A formação do professor de História e o cotidiano da sala de aula. IN: BITTENCOURT, C. O saber histórico em sala de aula. São Paulo: Contexto, 1997, p. 54-66. 


\section{ANPUH: contributions and limits in the definitions on History teaching}

\section{ABSTRACT}

The text analyzes the participation of the National Association of History ANPUH, in the Diagnosis and Evaluation of the History courses in Brazil (19811986) and the contributions for the discussion on the professional of History that it wants to form, as well as it indicates some subjects on which it would be desirable the deepening of the debate.

Key-words: ANPUH, evaluation, professional of History. 